\title{
Résumés des Articles
}

Michael Shortland, L'art et la passion sur la scène anglaise au milieu $d u{ }_{1} 8^{e}$ siècle.

Il est généralement admis que la «révolution» qui eut lieu dans le théâtre anglais entre $174^{\circ}$ et $175^{\circ}$ marque un tournant décisif pour le jeu de l'acteur, le mode d'écriture dramatique et l'organisation des théâtres. Dans notre article, nous espérons élargir le débat en nous appuyant sur une lecture approfondie des traités contemporains sur l'art du comédien, sources souvent citées mais rarement étudiées. Ces ouvrages proposent un cadre à l'intérieur duquel les rappors entre acteurs et spectateurs se présentent sous un jour nouveau et ils offrent un point de vue qui permet de relier la vie théâtrale aux transformations socio-culturelles de cette époque. Ces traités d'art dramatique abondent en termes tels que «nature», «jeu naturel», "passion», «caractère», «rôles», etc.: autour de ces points de référence, deux styles de jeu bien distincts se sont développés, le style «imitatif» et le style "sensible». L'ạnalyse de ces deux tendances révèle qu'elles furent élaborées à l'intérieur d'un ensemble culturel dont participent les beaux-arts et la littérature et qu'elles furent circonscrites par ses mêmes facteurs. En comparaison, Le Paradoxe sur le comédien met au jour une notion de l'acteur et du jeu théâtral proprement intra-scénique, c'est-à-dire que Diderot ne fait appel dans son argumentation à aucune convention extérieure au théâtre.

\section{Tatsuro Ishii, L'acteur de Nô selon Zeami}

A l'apogée de sa carrière, Zeami définit l'idéal du jeu de l'acteur comme étant une communication interne, voire subliminale entre lui-même et le spectateur. Il souligne l'importance de la danse et de la musique dans l'apprentissage du métier et invite l'acteur à atteindre ou à imiter le tai (l'invisible), car c'est là que réside l'essence de son art.

Pour que le comédien tienne son esprit en éveil tout au long de sa carrière, Zeami lui conseille de ne jamais oublier l'état de shoshin, c'est-à-dire l'état d'esprit dans lequel il se trouvait à ses débuts. Riken no ken est un idéal esthétique fait de beauté et d'élégance et qui demande à l'acteur d'adopter vis-à-vis de son propre jeu le point de vue du spectateur. Zeami emprunte aussi quelques idées de base au bouddhisme zen pour construire une métaphysique du jeu théâtral. Il affirme que l'acteur chevronné atteint la perfection de son art lorsqu'il est capable de maîtriser l'état du $m u$ (néant) et l'état de senu-hima (immobilité [= non-mouvement]). 
Le rythme et l'atmosphère d'un spectacle Nô doivent être structurés aussi soigneusement qu'un ballet musical et chaque élément de l'ensemble doit également refléter cette structure que Zeami appelle le jo-ha-kyu. Finalement, selon Zeami, la perfection absolue est atteinte quand l'acteur est capable d'aller au-delà de sa discipline et de sa technique.

\section{Richard Emmert, La formation de l'acteur de $\mathcal{N} \hat{o}$}

La formation de l'acteur du Nô japonais repose sur une tradition centenaire et se poursuit pendant de longues années, puisqu'elle peut durer jusqu'à trente ans et que, selon Zeami, elle devrait durer toure la vie. Dans le Japon contemporain, des amateurs aussi bien que des professionnels appartenant à des lignées d'acteurs étudient le Nô. Les amateurs sont généralement des femmes et, jusqu'ici, elles devaient financer elles-mêmes leurs études, alors que les professionnels sont des fils de famille d'acteurs de Nô et leur formation est gratuite. Traditionnellement l'éducation théâtrale formelle du jeune garçon commence le $6^{\mathrm{e}}$ jour $\mathrm{du} 6^{\mathrm{e}}$ mois après son $6^{\mathrm{e}}$ anniversaire et le premier stage dure jusqu'à sa $15^{\mathrm{e}}$ année. L'enseignement se fait par imitation du maître et en représentations publiques. Le second stage (uchidesi) dure environ jusqu'au $25^{\mathrm{c}}$ anniversaire de l'apprenti et pendant cette dizaine d'années, il s'entraîne individuellement sous la direction d'un maître qui est aussi un acteur de Nô. Il apprend le répertoire, travaille sa voix et l'expression corporelle et joue des rôles courts mais importants. Pour achever sa formation, il interprète les grands rôles et assimile les règles de conduite très strictes et très compliquées qu'un acteur de Nô doit observer au cours de sa préparation avant d'entrer en scène. C'est alors seulement qu'il sera officiellement reconnu comme acteur de Nô.

A cause de l'engouement actuel pour le Nô, certains acteurs sont surmenés de travail et, pour faire face, le gouvernement japonais offre une bourse à ceux qui désirent suivre un cours accéléré de trois ans. Il est à craindre que cette démarche ne porte un coup mortel à une tradition séculaire.

\section{Tatsuro Ishii, Le festival de Kasuga Wakamiya}

Kasuga Wakamiya no On-matsuri est un gigantesque festival qui a lieu chaque année depuis 850 ans dans la ville de Nara, l'ancienne et première capitale du Japon. Ce festival, dédié à la divinité de Kasuga Wakamiya, est une source précieuse pour la recherche théâtrale japonaise, car il perpétue des traditions ancestrales, non seulement du théâtre mais aussi de la danse et des rituels shintoïstes. Malgré une rapide occidentalisation, le 
Japon garde encore de nombreux festivals traditionnels, mais aucun ne contient des richesses comparables au point de vue de l'organisation du cortège et des festivités théâtrales et religieuses. Notre article présente le déroulement des événements et décrit le contexte dans lequel se place le festival.

\section{Tony Pearson, Evreinoff et Pirandello}

L'apport d'Evreinoff, homme de théâtre complet, à l'art théâtral du $20^{\mathrm{e}}$ siècle n'a pas obtenu la notoriété qu'il mérite, alors qu'il devrait figurer aux côtés de Stanislavsky, Meyerhold, Craig et Reinhardt. Depuis la publication de ses premiers écrits théoriques en 1908 jusqu'à sa mort survenue en 1953, Evreinoff a constamment défendu la notion de «théâtralité» basée sur «l'instinct théâtral», «la convention théâtrale», «le monodrame», «le théâtre dans la vie» et «le théâtre en soi». Dans cette recherche il rejoint Pirandello à qui il dut de voir ses pièces jouées en France et en Italie. Au début des années vingt, les deux dramaturges, venant d'horizons culturels éloignés, ont créé en même temps une trilogie du "théâtre dans le théâtre» et la première pièce de chaque trilogie est leur chef-d'œuvre: Six personnages en quête d'auteur et La Comédie du bonheur. Ces trilogies mettent en scène l'idée que le théâtre est une force indispensable à la vie et elles posent d'une façon nouvelle la question des rapports fondamentaux entre l'œuvre d'art et la réalité. Les deux auteurs/ théoriciens proposent en fait une «méta-dramaturgie» englobant scène et salle et dans laquelle le spectateur devient «acteur/participant» et l'acteur "acteur/spectateur".

La première partie de notre article, publiée ici, trace le développement d'Evreinoff durant sa période russe, jusqu'en 1925, et propose des parallèles avec le priandellisme. La deuxième partie sera consacrée à un examen plus approfondi des idées esthétiques et philosophiques de $L a$ Comédie du bonheur et des Six personnages en quête d'auteur. 